\title{
Highly improved hydration level sensing properties of Copper Oxide films with Sodium and Potassium doping Bünyamin Sahin ${ }^{1,2}$ and Tolga Kaya ${ }^{2,3}$ \\ ${ }^{1}$ Department of Physics, Faculty of Arts and Sciences, Mustafa Kemal University, Hatay, 31034, Turkey \\ ${ }^{2}$ School of Engineering and Technology, Central Michigan University, Mt. Pleasant, 48859, USA \\ ${ }^{3}$ Science of Advanced Materials Program, Central Michigan University, Mt. Pleasant, 48859, USA
}

\begin{abstract}
In this study, un-doped, Na-doped, and $\mathrm{K}$-doped nanostructured $\mathrm{CuO}$ films were successfully synthesized by the successive ionic layer adsorption and reaction (SILAR) technique and then characterized by scanning electron microscopy (SEM), X-ray diffraction (XRD) and Currentvoltage (I-V) measurements. Structural properties of the $\mathrm{CuO}$ films were affected from doping. The XRD pattern indicates the formation of polycrystalline $\mathrm{CuO}$ films with no secondary phases. Furthermore, doping affected the crystal structure of the samples. The optimum conductivity values for both $\mathrm{Na}$ and $\mathrm{K}$ were obtained at $4 \mathrm{M} \%$ doping concentrations. The comparative hydration level sensing properties of the un-doped, Na-doped, and $\mathrm{K}$-doped $\mathrm{CuO}$ nanoparticles were also investigated. A significant enhancement in hydration level sensing properties was observed for both $4 \mathrm{M} \% \mathrm{Na}$ and $\mathrm{K}$-doped $\mathrm{CuO}$ films for all concentration levels. Detailed discussions were reported in the study regarding atomic radii, crystalline structure, and conductivity.
\end{abstract}

Keywords: Artificial Sweat, Biosensor, Hydration, $\mathrm{CuO}$

a) Corresponding Author: Bünyamin ŞAHIN, E-mail: sahin38@gmail.com 


\section{Introduction}

In recent years, nanoscaled metal oxide thin films have attracted researcher's interest extensively in various fields including but not limited to electronics, optoelectronics, and sensors [1, 2]. Nanostructured copper oxide $(\mathrm{CuO})$, in particular, has been one of the most explored metal oxides thanks to their non-toxicity and excellent chemical stability. $\mathrm{CuO}$ is a p-type semiconductor with a narrow band gap of $1.3 \mathrm{eV}[3]$.

Physical properties of $\mathrm{CuO}$ films rely on their morphology, crystallite size, and distribution which are strongly dependent on the preparation method. A broad variety of techniques have been utilized for the deposition of nanostructured $\mathrm{CuO}$ films such as molecular beam epitaxy [4], chemical vapor deposition [5], pulsed laser deposition [6], sol-gel [7], ultrasonic spray pyrolysis [8], and SILAR (Successive Ionic Layer Adsorption and Reaction) [3]. SILAR is cheaper and easier and done at low-temperature comparing to traditional approaches that require advanced processing. Furthermore, SILAR method offers simplicity, reproducibility, environment friendly and safe manufacturability, and large area deposition suitability [3, 9].

Besides preparation methods, physical properties of $\mathrm{CuO}$ films can also be altered by addition of dopants. Doping, in general, is a powerful technique for optimizing the sensing properties of metal oxide semiconductors. Indeed, researchers have recently focused on the investigations of un-doped and doped nanostructured metal oxide films. For example, doping with alkali metals such as Sodium and Potassium enhances the conductivity, sensitivity and selectivity of humidity sensors [10-12]. It was reported that doping thin films with alkali metals affects luminescence and electrical properties of films $[13,14]$. Also, alkali metals are highly reactive hence can easily be oxidized which makes them even more suitable dopant for metal oxide nanostructures 
[15]. In the case of sweat sensing applications, Sodium and potassium can be considered as viable dopants as they are major components in human sweat [11, 16-20].

Excessive sweating is the major reason for dehydration during physical activities, especially in hot and humid conditions [17]. Sweating is a natural as well as an effective way of regulating the body temperature, but causes water and electrolytes (mainly $\mathrm{Na}^{+}, \mathrm{Cl}^{-}$and $\mathrm{K}^{+}$) loss from the body [18]. Dehydration and electrolyte imbalance have vital importance to particularly endurance athletes $[19,20]$. Therefore, continuous and real-time analysis of sweat may be used to detect changes in sweat composition as a warning indicator [21].

Metal doped $\mathrm{CuO}$ thin films have yet to be investigated for their hydration level detection properties except some preliminary studies on partially artificial sweat doped films [16]. In this study we focused on incorporating sodium and potassium ions as dopants and investigated the effect on sweat sensing properties of $\mathrm{CuO}$ films. A detailed investigation has been carried out on the structural, morphological, electrical, and sensing properties of sodium and potassium doped $\mathrm{CuO}$ films prepared by SILAR technique.

\section{Experimental details}

\subsection{Preparation of Artificial Sweat and Film deposition}

It is known that sweat $\mathrm{pH}$ is regulated by the human body and ranges between 5 and 7 . Consistent with the human physiology, the standard for the artificial sweat preparation (European standard EN1811: 2012 [22]) suggests to adjust the $\mathrm{pH}$ to 5.4. Therefore, the $\mathrm{pH}$ of the prepared artificial sweat solutions were adjusted accordingly with a maximum deviation of 0.3. Although sweat consists hundreds of components, as the standard depicted, only four ingredients were used which are $0.5 \%$ of sodium chloride (VWR), $0.1 \%$ of potassium chloride 
(VWR), $0.1 \%$ of lactic acid (VWR), and $0.1 \%$ of urea (Fisher Scientific). These solutions were prepared in deionized water in weight/volume ratios. $\mathrm{pH}$ value was adjusted to $5.4 \pm 0.3$ by adding $0.001 \mathrm{M}$ ammonium hydroxide (Fisher Scientific). EcoTestr PH2 pH meter was used for $\mathrm{pH}$ measurements.

Un-doped and doped nanostructured $\mathrm{CuO}$ films were grown on glass slides by using SILAR method. The glass substrates were cleaned using dilute sulfuric acid solution (H2SO4:H2O, 1:5 by volume) followed by acetone and double distilled water rinse $[2,15]$. Deionized (DI) water was used in all solution preparations. A DI water with a double distillation filtration system was used where the resistivity is set at $18.2 \mathrm{MOhm} \mathrm{cm}$. Using DI water ensures that the prepared solutions only contain the compounds that are added such as ions. Un-doped $\mathrm{CuO}$ films were prepared as the following: In order to obtain $0.1 \mathrm{M}$ Coper Chloride solution, $1.7 \mathrm{~g}$ of copper (II) chloride dihydrate (chemical symbol given as $\mathrm{CuCl} 2 \cdot \mathrm{H} 2 \mathrm{O}$ ) were weighed and mixed with 100 $\mathrm{mL}$ of DI. $0.1 \mathrm{M}$ Coper Chloride solution was prepared by using a magnetic stirring hot plate at room temperature with copper(II) chloride dehydrate $\left(\mathrm{CuCl}_{2} 2 \mathrm{H}_{2} \mathrm{O}\right)$ and $100 \mathrm{ml}$ double distilled water $(18.2 \mathrm{M} \Omega \mathrm{cm}) . \mathrm{pH}$ value of the solution was then adjusted to around 10.0 by adding aqueous ammonia and the solution was heated up to $90{ }^{\circ} \mathrm{C}$. Temperature was kept constant during the film growth process. The cleaned glass substrates were immersed into the solution containing $\mathrm{Cu}^{+2}$ and kept there for $20 \mathrm{~s}$. They were then taken out from the bath and immediately dipped into hot water $\left(90^{\circ} \mathrm{C}\right)$ for another $20 \mathrm{~s}$. This cycle was repeated 12 times. Same procedure was followed for the doped $\mathrm{CuO}$ films with the exception of addition of $\mathrm{Na}^{+}$and $\mathrm{K}^{+}$into copper chloride solutions. Various ion dopant concentrations were prepared in molar percentages of 2, 4, 6 and $8 \mathrm{M} \%$. 


\subsection{Characterization of the films}

A Hitachi $3400 \mathrm{~N}$-II scanning electron microscope (SEM) was used for morphological imaging of un-doped and doped $\mathrm{CuO}$ films. Crystal structures of the samples were examined by X-ray diffractometer (XRD) (Rigaku Miniflex II). Resistivity values of the $\mathrm{CuO}$ films were determined by using room temperature I-V measurements with Keithley 617 electrometer. Sweat sensing properties of un-doped and doped $\mathrm{CuO}$ films were investigated by dropping $15 \mu \mathrm{l}$ of artificial sweat solution with different concentrations on the surface. Resistivity measurements were used to determine the performance of the sensors. Concentrations of artificial sweat were selected to be $13.10,20.96,26.20,52.40$ and $104.8 \mathrm{mM}$.

\section{Results and discussion}

\subsection{Morphological and microstructural analyses}

The surface topographies of un-doped and doped $\mathrm{CuO}$ films were investigated by examining the SEM results (Figs. 1 and 2). Fig. 1 shows SEM images of the un-doped $\mathrm{CuO}$ film for two different magnifications. It is clear from Fig. 1 that the film is highly dense with uniform surface and the nano-sized structure are well dispersed on the substrate without any cracks. There are plate-like $\mathrm{CuO}$ nanostructures which cover the substrate homogenously.

The SEM micrographs of doped films in Fig. 2 show that the surfaces are homogenous and densely packed similar to Fig. 1 . We observed from Fig. 2 that surface properties of the $\mathrm{CuO}$ films with different doping levels of Sodium and Potassium were slightly modified comparing to the un-doped film. The changes in morphologies can be attributed to the difference in ionic radius of dopant elements (Na: $116 \mathrm{pm}$ and $\mathrm{K}: 152 \mathrm{pm})$ and copper $(\mathrm{Cu}: 97 \mathrm{pm})$, which affect the 
growth process of crystal structure. The larger ionic radius of $\mathrm{K}$ as compared to ionic radius of $\mathrm{Cu}$, would induce an expansion in lattice parameters of doped $\mathrm{CuO}$. Thus, the presence of $\mathrm{K}$ and $\mathrm{Na}$ accelerates the phase of $\mathrm{CuO}$ peak [23]. As seen in our results, incorporation of $\mathrm{Na}$ and $\mathrm{K}$ in $\mathrm{CuO}$ films had a clear effect on surface morphology. The change in particle size can be attributed to the significant increase in ionic radius (from $97 \mathrm{pm}$ to $152 \mathrm{pm}$ ) between $\mathrm{Cu}$ and $\mathrm{K}$. These results are also supported with XRD observations below. The density as well as the length of the nano-plates were observed to be increasing with doping. Length change, in particular, is more apparent for potassium doping. These changes combined affected the crystalline structure and electrical properties of the $\mathrm{CuO}$ films.

Structural properties of $\mathrm{CuO}$ films such as structural identity and crystallinity quality were investigated by XRD and given in Fig. 3 and Fig. 4. All the diffraction peaks can be indexed to the monoclinic phase of $\mathrm{CuO}$ crystals [JCPDS 01-080-0076]. Fig. 3 shows the XRD pattern of Na-doped $\mathrm{CuO}$ films with different concentrations of sodium. The XRD pattern of un-doped $\mathrm{CuO}$ film was also included in Fig. 3 for comparison. Un-doped $\mathrm{CuO}$ samples indicate the diffraction angles at $2 \theta$ value of $32.4^{\circ}, 35.4^{\circ}, 38.5^{\circ}, 48.8^{\circ}, 53.4^{\circ}, 66.4^{\circ}$, and $68.0^{\circ}$ corresponding to (110), (111), (111), (202), (020), (113), and (022) CuO crystal planes, respectively. There are no secondary phases observed. The peak intensities of $\mathrm{CuO}$ films slightly increased with $\mathrm{Na}$ doping that could perhaps be due to the occupation of oxygen vacancies by Sodium anions [24]. XRD results in Fig. 3 showed strong preferential orientation in (111) and (111) directions. XRD peaks narrow down with Sodium doping which indicates higher crystallinity quality compared with the un-doped $\mathrm{CuO}$ film. 
Fig. 4 shows the $\mathrm{XRD}$ pattern of $\mathrm{K}$-doped $\mathrm{CuO}$ films with un-doped $\mathrm{CuO}$ film as the baseline. Similar to Sodium doping, no extra peaks (i.e. phases) were detected with potassium doping. As doping concentration increases, the peak intensities become more intense and sharper indicating a good crystallinity quality. Figs. 3 and 4 prove that $\mathrm{Na}$ and $\mathrm{K}$ atoms scatter homogenously in the $\mathrm{CuO}$ lattice because no peaks belonging to other oxide forms of $\mathrm{Cu}, \mathrm{Na}$ and $\mathrm{K}$ are observed. Although there is not a clear shift of $2 \theta$ in (111) diffraction was observed from Figs. 3 and 4 , obtained diffraction data showed a slight shift towards higher Bragg angle from 35.495 (for undoped $\mathrm{CuO}$ ) to 35.554 (for Na-doped) and 35.754 (for K-doped). These peak shifts towards the higher angle appears due to the created structural strain from doping [25]. Doping causes a shift in the peak due to the decrease in crystal lattice constant. This change is perhaps due to the occupation of $\mathrm{Na}$ and $\mathrm{K}$ atoms on the $\mathrm{CuO}$ site [26].

\subsection{Electrical Characterization}

It is known that doping levels significantly affect the electrical properties of metal oxide films [27-29]. Therefore, we studied different doping levels (from $2 \mathrm{M} \%$ to $8 \mathrm{M} \%$ ) in order to determine the optimum doping concentration to obtain better sensitivity of $\mathrm{CuO}$ films to artificial sweat. Fig. 5 shows the sheet resistance values of the un-doped and doped $\mathrm{CuO}$ films as a function of $\mathrm{Na}$ and $\mathrm{K}$ molar ratios of 2, 4, 6 and $8 \mathrm{M} \%$. Here, the concentration values are calculated as a function of the molarity of the dopant. It is clear from Fig. 5 that the resistivity values of the films strongly depend on the doping levels. For both $\mathrm{Na}$ and $\mathrm{K}$ doping, resistivity values seem to be reaching a local minimum at $4 \mathrm{M} \%$. Besides this concentration, there is an increasing trend in resistivity with higher dopant levels. It must be noted here that this observation is done with 4 data points, hence the trends might be slightly different with a full 
spectrum of dopant analysis, which is outside the scope of this paper. Regardless, It must also be noted that the resistivity values for all the doped films are much lower than the un-doped $\mathrm{CuO}$ film, which is expected.

It is expected that the resistivity values decrease with higher doping concentrations as a result of increased density of free electrons coming from the dopant. However, Fig. 5 shows that this expectation has not been satisfied after $4 \mathrm{M} \%$ for $\mathrm{CuO}$ films. This is mainly due to the creation of carrier traps in the lattice that reduced the mobility [30-32]. For low concentrations, these traps do not exist because dopant ions are effectively replaced with $\mathrm{Cu}$ ions in the films which can enhance the carrier concentration. Moreover, higher concentration of doping levels cause ionized impurity scattering centers in $\mathrm{CuO}$ films which is another reason in resistivity increase after $4 \mathrm{M} \%$ of doping $[33,34]$.

Another important observation from Fig. 5 is that $\mathrm{K}$-doped $\mathrm{CuO}$ films have consistently higher conductivity than Na-doped $\mathrm{CuO}$ films for the same doping concentration. It is known that the lattice parameter is dependent on the atomic radii of the dopant and the doped material [35]. In our case, atomic radius difference between $\mathrm{K}$ and $\mathrm{Cu}(243-157 \mathrm{pm}=86)$ is bigger than $\mathrm{Na}$ and $\mathrm{Cu}(190-157=33)$. Previous research showed that the electron conductivity enhances as the lattice parameter expands [36-38].

In order to evaluate the sensing performance of doped and un-doped $\mathrm{CuO}$ films, the sensing response, $S$, to different artificial sweat concentrations is defined using the equation below [39]:

$$
S=\frac{R_{\text {nom }}-R_{i}}{R_{\text {nom }}} \times 100
$$


where $S$ is the percentage change in resistivity of $\mathrm{CuO}$ films after the artificial sweat is dropped, (labeled as $R_{\mathrm{i}}$ ) with respect to the nominal resistivity ( $R_{\text {nom, }}$, no solution application). Fig. 6 shows the sensing response for $2 \mathrm{M} \%$ and $4 \mathrm{M} \% \mathrm{Na}$ - and $\mathrm{K}$-doped $\mathrm{CuO}$ films for artificial sweat concentrations from $13 \mathrm{mM}$ to $105 \mathrm{mM}$. This range was chosen to cover low and high concentration values of artificial sweat with respect to an average concentration which is around $60 \mathrm{mM}$. 2M\% Na-doped $\mathrm{CuO}$ film does not improve the sensing response significantly. Although 2M\% K-doped $\mathrm{CuO}$ film shows an improvement in sensing response in higher artificial sweat concentrations, lower concentrations of artificial sweat does not result in a consistent improvement in sensing response. Both 4M\% Na- and $\mathrm{K}$-doped $\mathrm{CuO}$ films showed significant enhancement in sensing response. This enhancement is more apparent for K-doped films. Sensing response increases $1.7 \pm 0.4$ times on average and $2.4 \pm 0.4$ times on average for 4M\% Na- and $\mathrm{K}$-doped $\mathrm{CuO}$ films, respectively, over a range of artificial sweat applications. Another important observation from Fig. 6 is that all $\mathrm{CuO}$ films respond the most at mid-range artificial sweat concentration, i.e. around $50 \mathrm{mM}$. As the added artificial sweat concentration increases, the $\mathrm{CuO}$ films reach a saturation due to the limited active sensing area thus decreasing the sensing response [39]. Overall, doping $\mathrm{CuO}$ films with $\mathrm{Na}$ and $\mathrm{K}$ ions increased the sensing response, which is consistent with previous studies $[24,40]$. 


\section{Conclusions}

In this study, we have investigated the hydration level sensing characteristics of un-doped and Na- and K-doped $\mathrm{CuO}$ films at room temperature. Un-doped and Na- and K-doped nanostructured $\mathrm{CuO}$ thin films were deposited on glass substrates by using SILAR technique. Various doping concentrations were experimented in order to optimize the sensing properties of doped $\mathrm{CuO}$ films. The SEM images revealed that the length and density of nano-plates were affected by doping. The XRD results confirmed that all the films show $\mathrm{CuO}$ crystalline structure and the influence of $\mathrm{Na}$ and $\mathrm{K}$-doping on the peak intensity and peak position. The electrical conductivity was found to be increased with $\mathrm{Na}$ and $\mathrm{K}$ doping with reaching a maximum at $4 \mathrm{M}$ $\%$. The sensing response of the films were investigated by drop casting artificial sweat solutions on the $\mathrm{CuO}$ films. The sensing response of doped films showed a significant improvement with respect to the un-doped $\mathrm{CuO}$ film, particularly for high artificial sweat concentrations. It is concluded that $\mathrm{Na}$ - and $\mathrm{K}$-doped $\mathrm{CuO}$ films show a great promise to be used for sweat sensing applications.

\section{Acknowledgements}

Partial funding was provided by the National Science Foundation (\#EEC-1201095) and The Scientific and Technological Research Council of Turkey (TUBITAK Grant \#2219). Dr. Axel Mellinger provided experimental guidance on IV measurements. Tommaso Costanzo and Dr. Gabriel Caruntu helped with XRD measurements. 


\section{References}

[1] G. A.M. Ali, O. A.G. Wahba, A. M. Hassan, O. A. Fouad, K. F. Chong, Calcium-based nanosized mixed metal oxides for supercapacitor application, Ceramics International 41 (2015) 8230-8234.

[2] B. Sahin, F. Bayansal, M. Yüksel, H.A. Çetinkara.Influence of annealing to the properties of un-doped and Co-doped CdO films, Materials Science in Semiconductor Processing, 18 (2014) 135-140.

[3] K. Mageshwari, R. Sathyamoorthy, Physical properties of nanocrystalline CuO thin films prepared by the SILAR method, Materials Science in Semiconductor Processing 16 (2013) 337343

[4] Z. Jin, M. Murakami, T. Fukumura, Y. Matsumoto, A. Ohtomo, M. Kawasaki, H. Koinuma, Combinatorial laser MBE synthesis of $3 \mathrm{~d}$ ion doped epitaxial $\mathrm{ZnO}$ thin films, J. Cryst. Growth $215(2000) 55-58$.

[5] L. Armelao, D. Barecca, M. Bertapelle, G. Bottaro, C. Sada, E. Tondello, A sol-gel approach to nanophasic copper oxide thin films, Thin Solid Films 442 (2003) 48-52.

[6] K. Masuko, A. Ashida, T. Yoshimura, N. Fujimura, Influence of antiferromagnetic exchange interaction on magnetic properties of $\mathrm{ZnMnO}$ thin films grown pseudomorphical on $\mathrm{ZnO}$ $\left(0001^{-}\right)$single-crystal substrates, Journal of Applied Physics 103 (2008) 043714.

[7] M. Yang, Z.X. Guo, K.H. Qiu, J.P. Long, G.F. Yin, D.G. Guan, S.T. Liu, S.J. Zhou, Synthesis and characterization of Mn-doped ZnO column arrays, Appl. Surf. Sci. 256 (2010) 4201-4205.

[8] I. Singh, R.K. Bedi, Studies and correlation among the structural, electrical and gas response 
properties of aerosol spray deposited self assembled nanocrystalline CuO, Applied Surface Science 257 (2011) 7592-7599.

[9] Y. Akaltun, T. Çayır, Fabrication and characterization of NiO thin films prepared by SILAR Method, Journal of Alloys and Compounds 625 (2015) 144-148.

[10] A. Tabib, N. Sdiri, H. Elhouichet, M. Férid, Investigations on electrical conductivity and dielectric properties of $\mathrm{Na}$ doped $\mathrm{ZnO}$ synthesized from sol gel method, Journal of Alloys and Compounds 622 (2015) 687-694.

[11] M. Al-Omari, K. Sel, A. Mueller, A. Mellinger, and T. Kaya, The effect of $\mathrm{Na}^{+}$and $\mathrm{K}^{+}$ doping on the properties of sol-gel deposited 2-hydroxy-1,4-naphthoquinone thin films, J. Appl. Phys. 113 (2013) 204901.

[12] Q. Qi, Y. Feng, T. Zhanga, X. Zheng, G. Lu, Influence of crystallographic structure on the humidity sensing properties of $\mathrm{KCl}$ doped TiO2 nanofibers, Sensors Actuators B, 139 (2009) $611-617$.

[13] S. Mageswari, L. Dhivya, B. Palanivel, R. Murugan, Structural, morphological and optical properties of $\mathrm{Na}$ and $\mathrm{K}$ dual doped CdS thin film, Journal of Alloys and Compounds 545 (2012) $41-45$.

[14] V. G. Klyuev, T. L. Maiorova, A. V. Naumov, V. N. Semenov, Luminescence and electrical properties of cds films doped with potassium and sodium, Journal of Applied Spectroscopy, Vol. $72(2005) 552-557$.

[15] B. Şahin, F. Bayansal, Facile synthesis of group-I elements (K, Li and Na) doped nanostructured CdO films; Philosophical Magazine 94 (2014) 4171-4180.

[16] B. Sahin, M.Alomari, T.Kaya. Hydration Detection through use of artificial sweat in dopedand partially-doped nanostructured $\mathrm{CuO}$ films, Ceramics International 41 (2015) 8002-8007. 
[17] B. Murray, Hydration and Physical Performance, The Journal of the American College of Nutrition, 26 (2007) 542-548.

[18] N.J. Rehrer, L.M. Burke, Sweat losses during various sports. Australian journal of nutrition and dietetics 53 (1996) 13-16.

[19] M.N. Sawka MN, S.J. Montain and W.A. Latzka, Hydration effects on thermoregulation and performance in the heat. Comparative Biochemistry and Physiology-Part A: Molecular \& Integrative Physiology, 12 (2001) 679-690.

[20] S.M. Shirreffs , R.L. Maughan, Whole body sweat collection in humans: an improved method with preliminary data on electrolyte content, Journal of Applied Physiology, 82 (1997) $336-341$.

[21] G. Liu, M. Alomari, B. Sahin, S. E. Snelgrove, J. Edwards, A. Mellinger, T. Kaya, Realtime sweat analysis via alternating current conductivity of artificial and human sweat, Applied Physics Letters 106 (2015) 133702.

[22] EN 1811:2011, Reference test method for release of nickel from all post assemblies which are inserted into pierced parts of the human body and articles intended to come into direct and prolonged contact with the skin, German version EN 1811:2011.

[23] A. Arunachalam, S. Dhanapandian, C. Manoharan, Effect of Sn doping on the structural, optical and electrical properties of TiO2 films prepared by spray pyrolysis, Physica E 76 (2016) 35-46.

[24] E. Şennik, S. Kerli, Ü. Alver, Z. Z. Öztürk, Effect of fluorine doping on the $\mathrm{NO}_{2}$-sensing properties of ZnO thin films, Sensors and Actuators B 216 (2015) 49-56.

[25] A.A. Dakhel, Optoelectronic properties of Eu- and H-codoped CdO films, Current Applied Physics 11 (2011) 11-15. 
[26] G. Shanmuganathan, I.B. S. Banu, S. Krishnan, B. Ranganathan, Influence of K-doping on the optical properties of $\mathrm{ZnO}$ thin films grown by chemical bath deposition method, Journal of Alloys and Compounds 562 (2013) 187-193.

[27] Chi-Jung Chang, Chang-Yi Lin, Jem-Kun Chen, Mu-Hsiang Hsu, Ce-doped ZnO nanorods based low operation temperature NO2 gas sensors, Ceram. Int. 40 (2014) 10867-10875.

[28] F. Yang, Z. Guo, Comparison of the enhanced gas sensing properties of tin dioxide samples doped with different catalytic transition elements, Journal of Colloid and Interface Science 448 (2015) 265-274.

[29] C.-H. Han, S.-D. Han, S.P. Khatkar, Enhancement of H2-sensing properties of F-doped $\mathrm{SnO} 2$ sensor by surface modification with $\mathrm{SiO}_{2}$, Sensors 6 (2006) 492-502.

[30] K. Sankarasubramanian , P.Soundarrajan , T.Logu, S.Kiruthika, K. Sethuraman, R.R. Babu, K.Ramamurthi, Influence of Mn doping on structural, optical and electrical properties of $\mathrm{CdO}$ thin films prepared by cost effective spray pyrolysis method, Materials Science in Semiconductor Processing 26 (2014) 346-353.

[31] C.M. Muiva, T.S. Sathiaraj, K. Maabong, Effect of doping concentration on the properties of aluminum doped zinc oxide thin films prepared by spray pyrolysis for transparent electrode applications, Ceramics International 37 (2011) 555-560.

[32] K.T. Kim, G.H.Kim, J. C.Woo, C. I.Kim, Characteristics of nickel-doped zinc oxide thin films prepared by sol-gel method, Surface and Coating Technology 202 (2008)5650-5653.

[33] B.J. Zheng, J.S. Lian, L. Zhao, Q. Jiang, Optical and electrical properties of Sn-doped CdO thin films obtained by pulse laser deposition, Vacuum 85 (2011) 861-865.

[34] R. Ferro , J. A. Rodriguez, O. Vigil, A. Morales-Acevedo, G. Contreras-Puente, F-Doped CdO Thin Films Deposited by Spray Pyrolysis, Physica status solidi (a) 177, (2000) 477-483. 
[35] G. Xiao, S. Nuansaeng, L. Zhang, S. Suthirakun, A. Heyden, Enhanced Reducibility and Conductivity of $\mathrm{Na} / \mathrm{KDoped} \mathrm{SrTi}_{0.8} \mathrm{Nb}_{0.2} \mathrm{O}_{3}$ Journal of Materials Chemistry A, 1 (2013) 1054610552.

[36] X. Li, M.Z. Qu, Z.L. Yu, Structural and electrochemical characteristics of Li4-xKxTi5O12 as anode material for lithium-ion batteries. Chin J Inorg Chem 26 (2010) 233-239

[37] C.H. Chen, J.T. Vaughey, A.N. Jansen, D.W. Dees, A.J. Kahaian, T. Goacher, M.M. Thackeray, Studies of Mg-Substituted Li4-xMgxTi5O12 Spinel Electrodes $(0 \leq x \leq 1)$ for Lithium Batteries Journal of Electrochemical Society 148 (2001) 102-104.

[38] Q.Y. Zhang, C.L. Zhang, B. Li, S.F. Kang, X. Li, Y.G. Wang, Preparation and characterization of W-doped Li4Ti5O12 anode material for enhancing the high rate performance Electrochimica Acta 98 (2013) 139-146.

[39] M. Parmar , R. Bhatia , V. Prasad, K. Rajanna, Ethanol sensing using CuO/MWNT thin film, Sensors and Actuators B 158 (2011) 229-234

[40] N. Kılınc, , S. Öztürk, L. Arda, A. Altındal, Z.Z. Öztürk, Structural, electrical transport and $\mathrm{NO}_{2}$ sensing properties of Y-doped $\mathrm{ZnO}$ thin films, J. Alloys Compd. 536 (2012) 138-144. 


\section{Resistivity}

\section{SEM images of un-doped $\mathrm{CuO}$} films

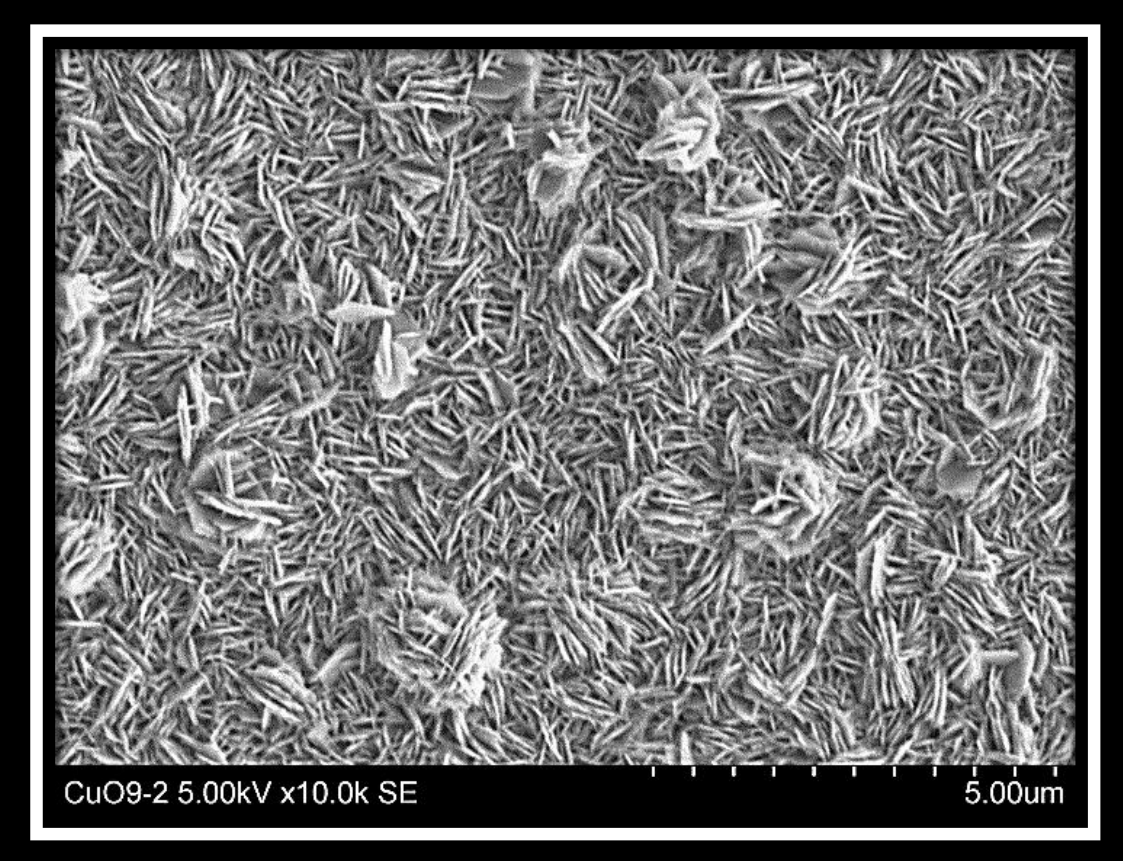

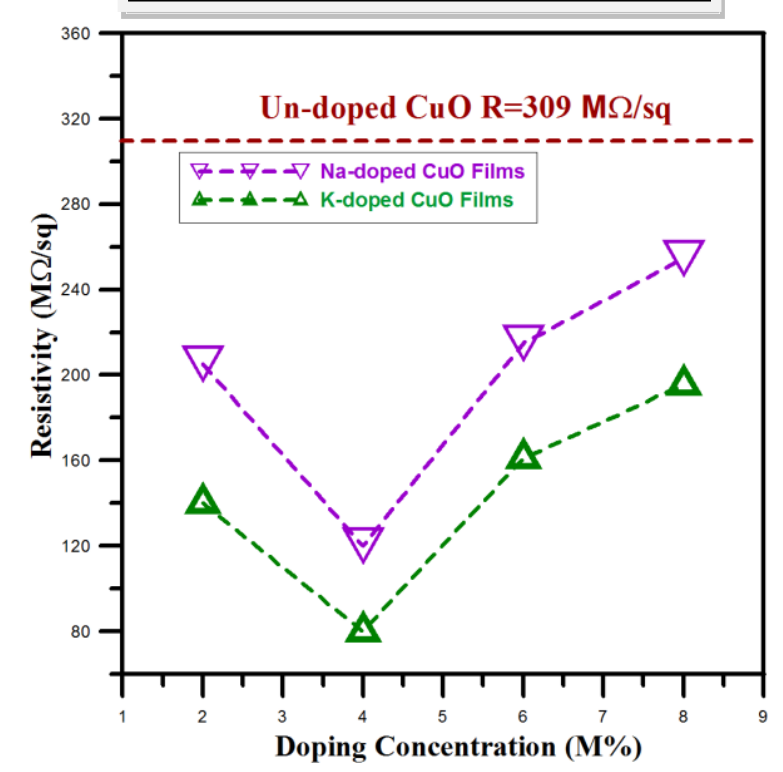

\section{Sensing Response}

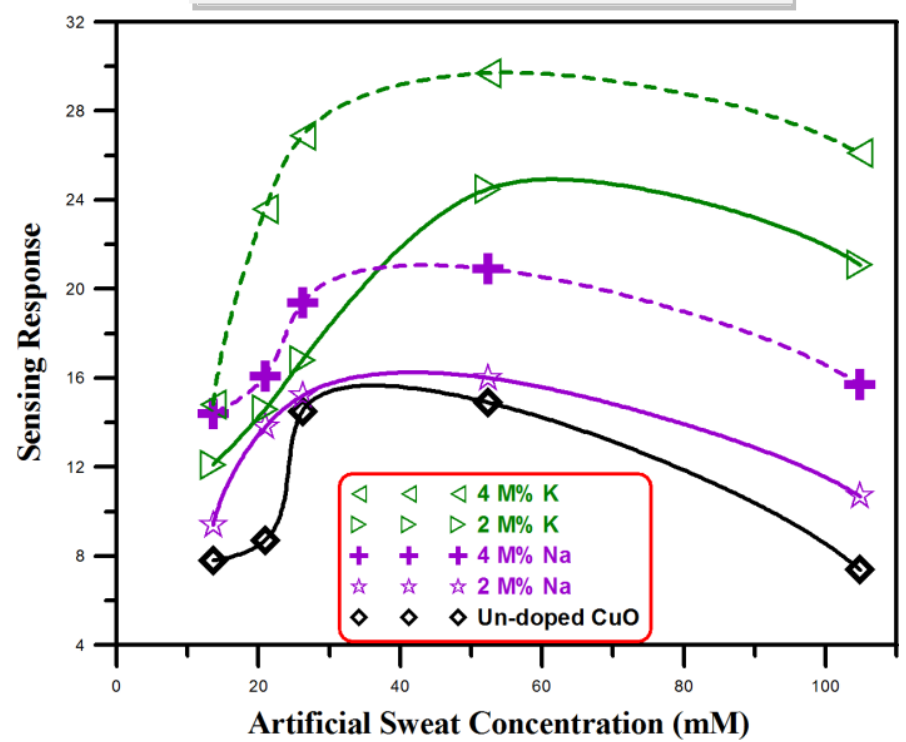



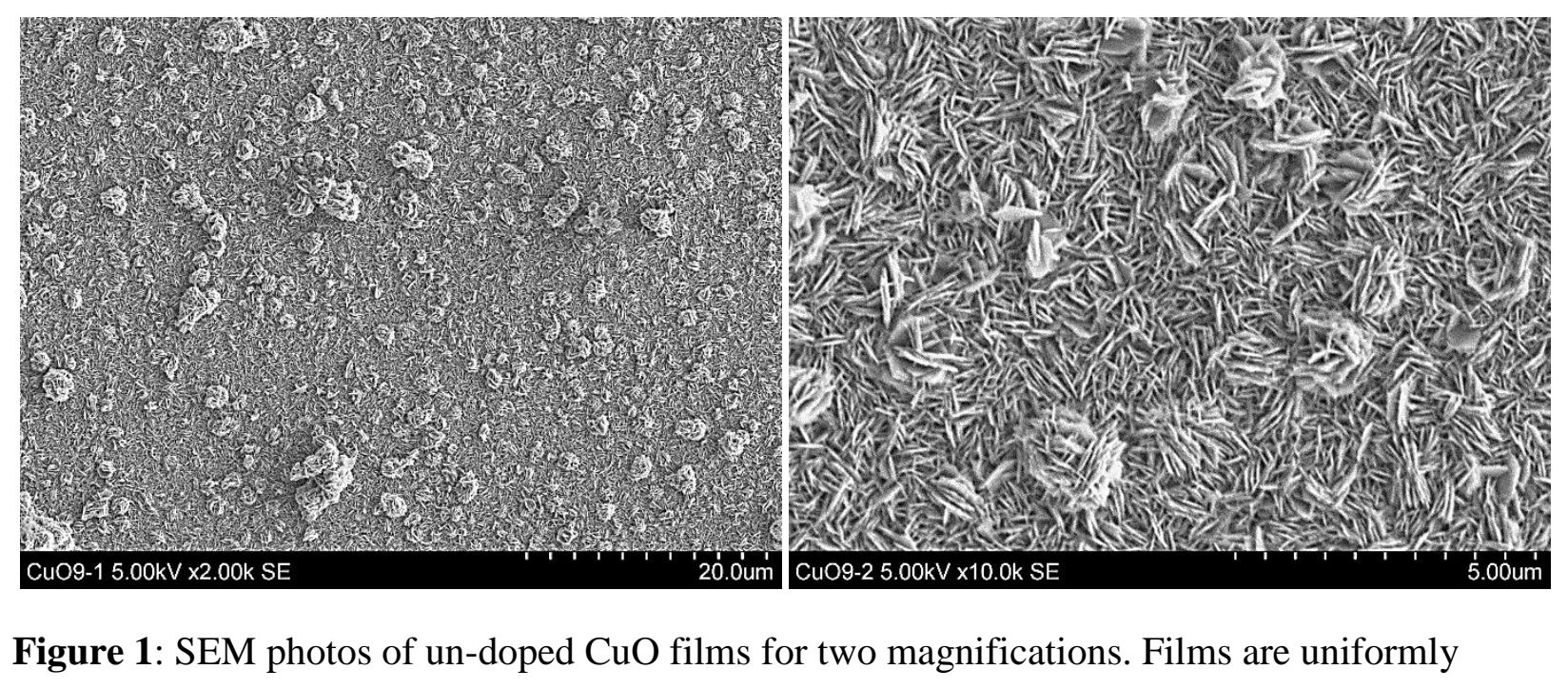

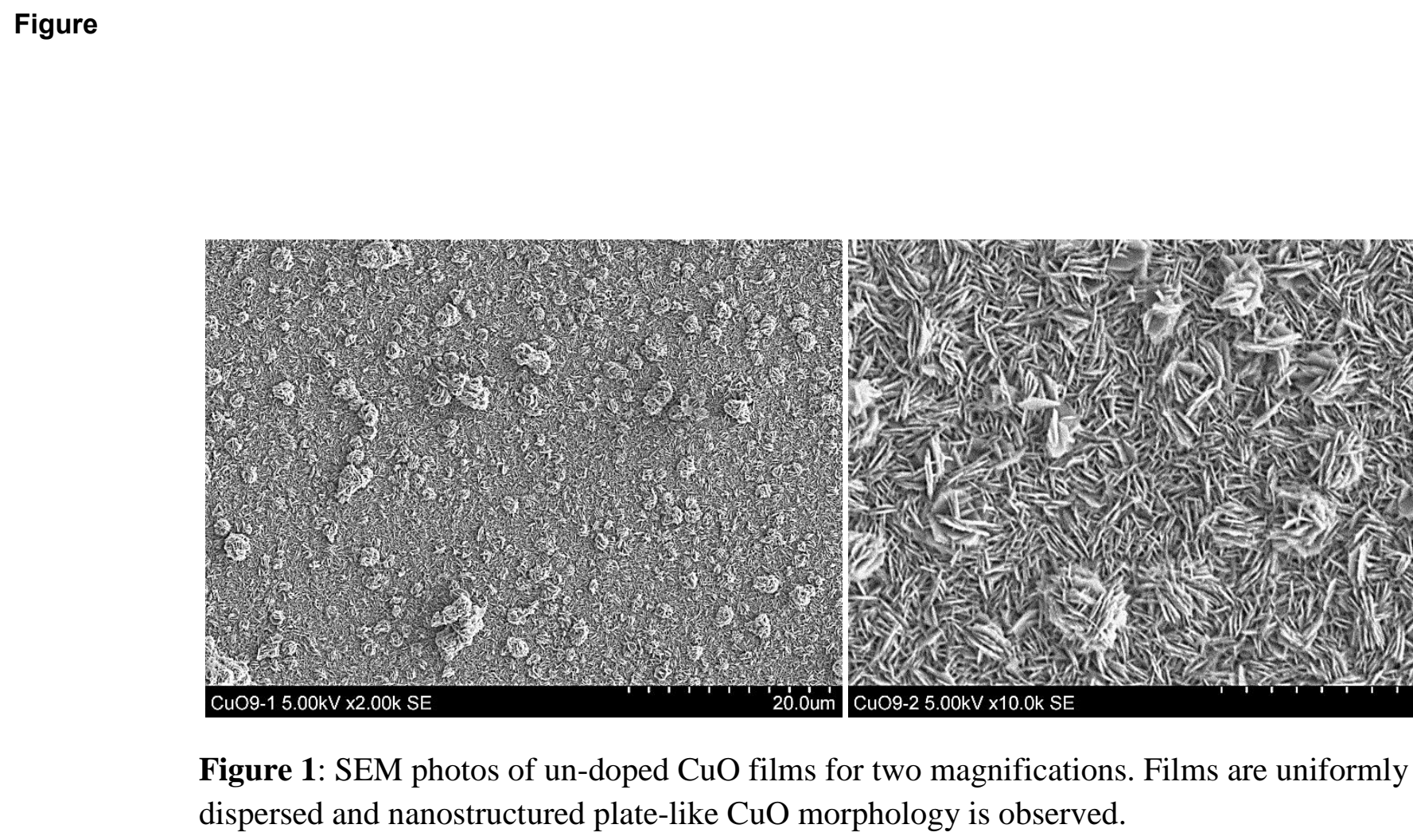

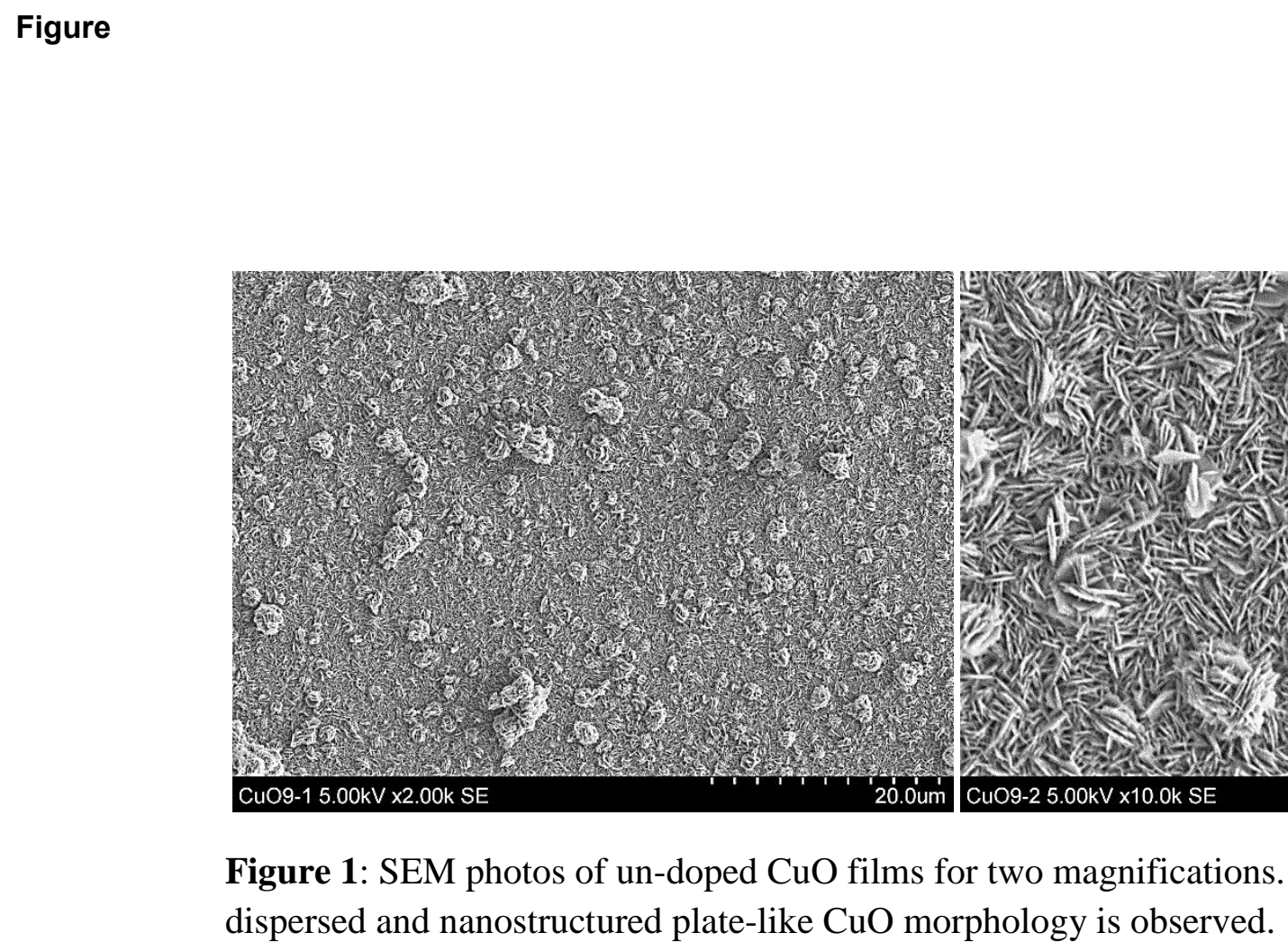

cispersed and nanostructured plate-like CuO morphology is observed.

.



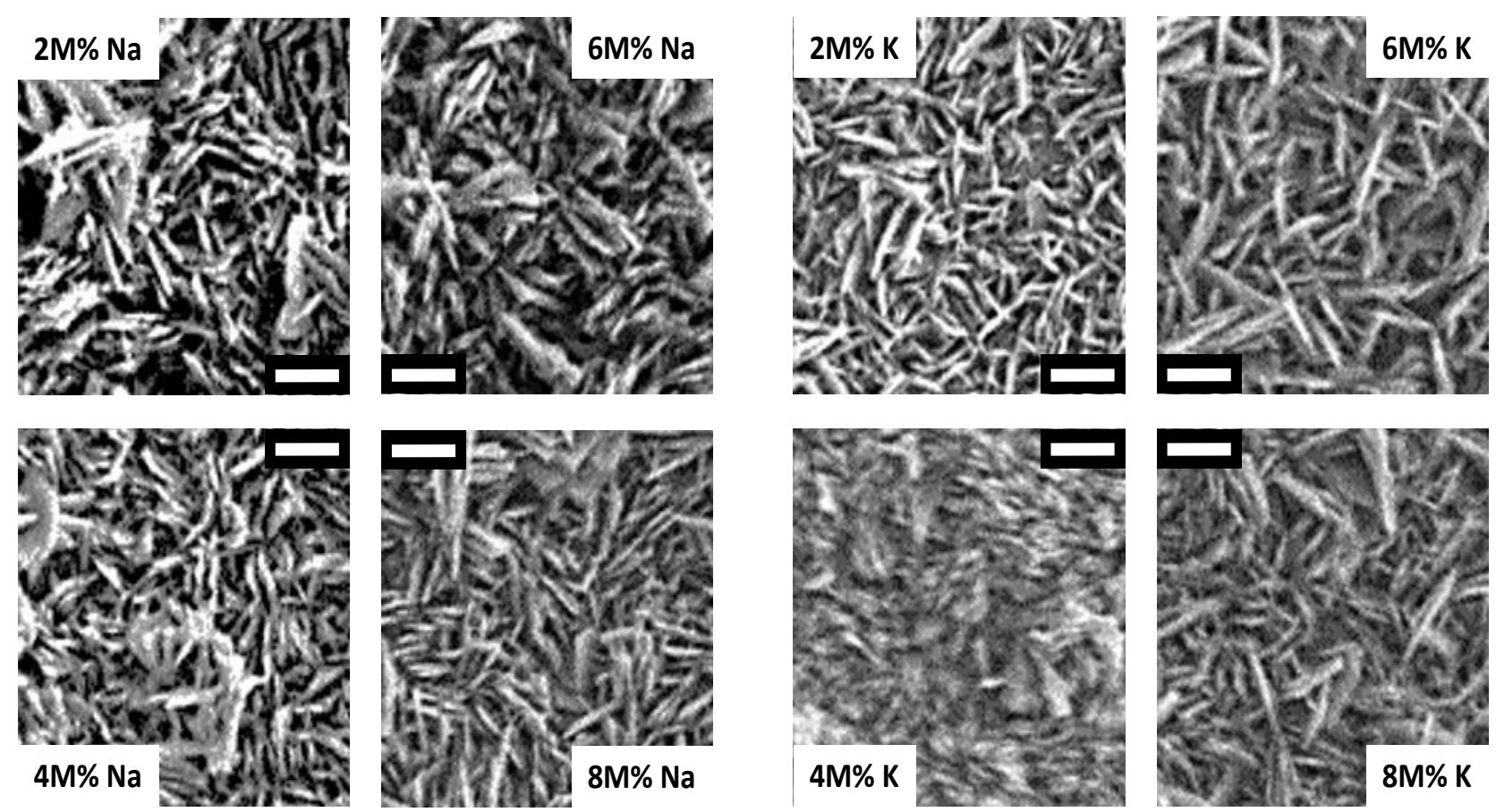

Figure 2: SEM photos of various doping concentrations for $\mathrm{Na}$ and $\mathrm{K}$. The scale bars are $2 \mu \mathrm{m}$ in length. For both metal doped films, increasing doping caused denser films. Also, length of the nanoplates increased particularly for $\mathrm{K}$. 


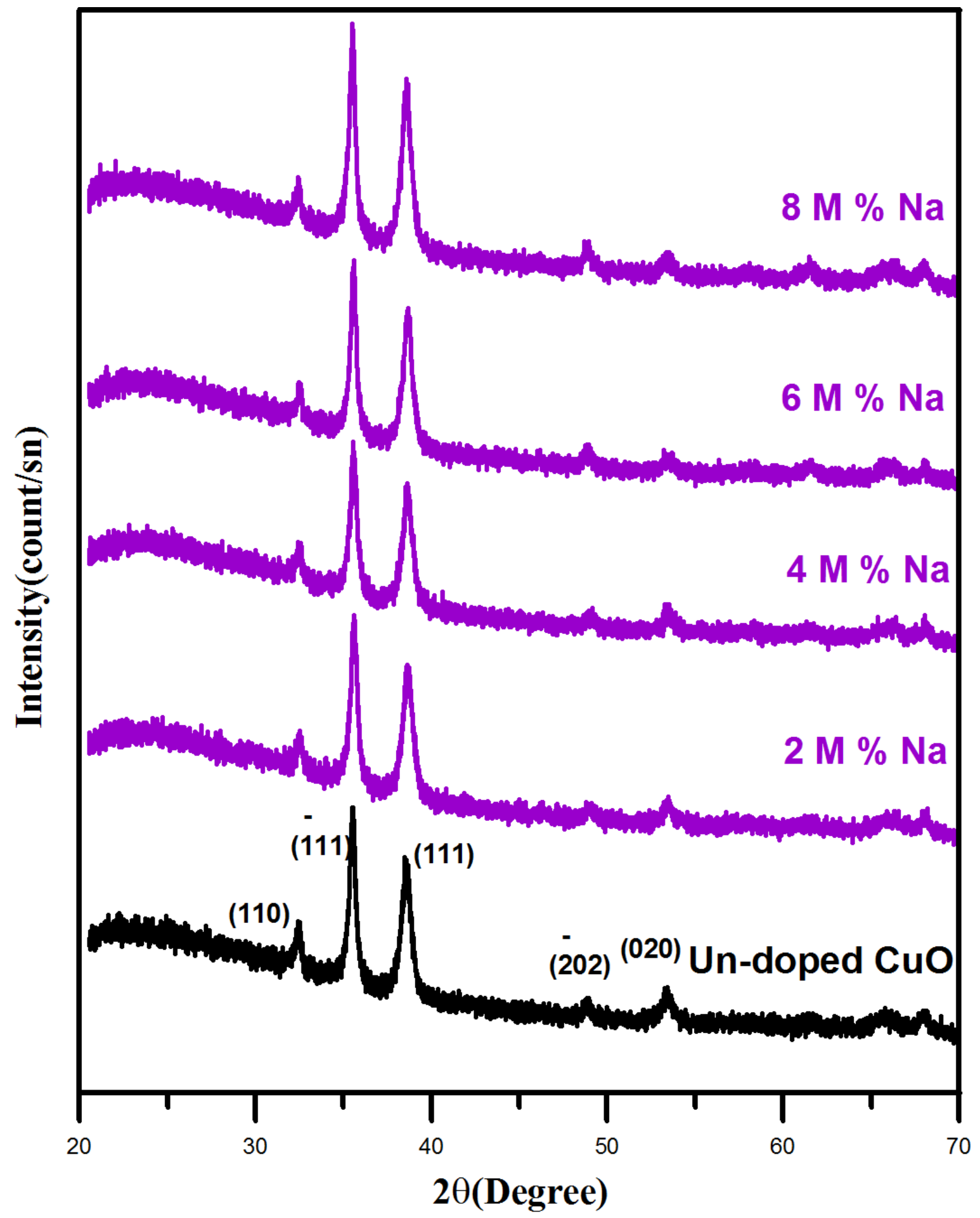

Figure 3: XRD patterns for Na-doped $\mathrm{CuO}$ films. The peak intensity increases with doping suggesting better crystallinity. The XRD pattern of the un-doped $\mathrm{CuO}$ film is also included for comparison. 


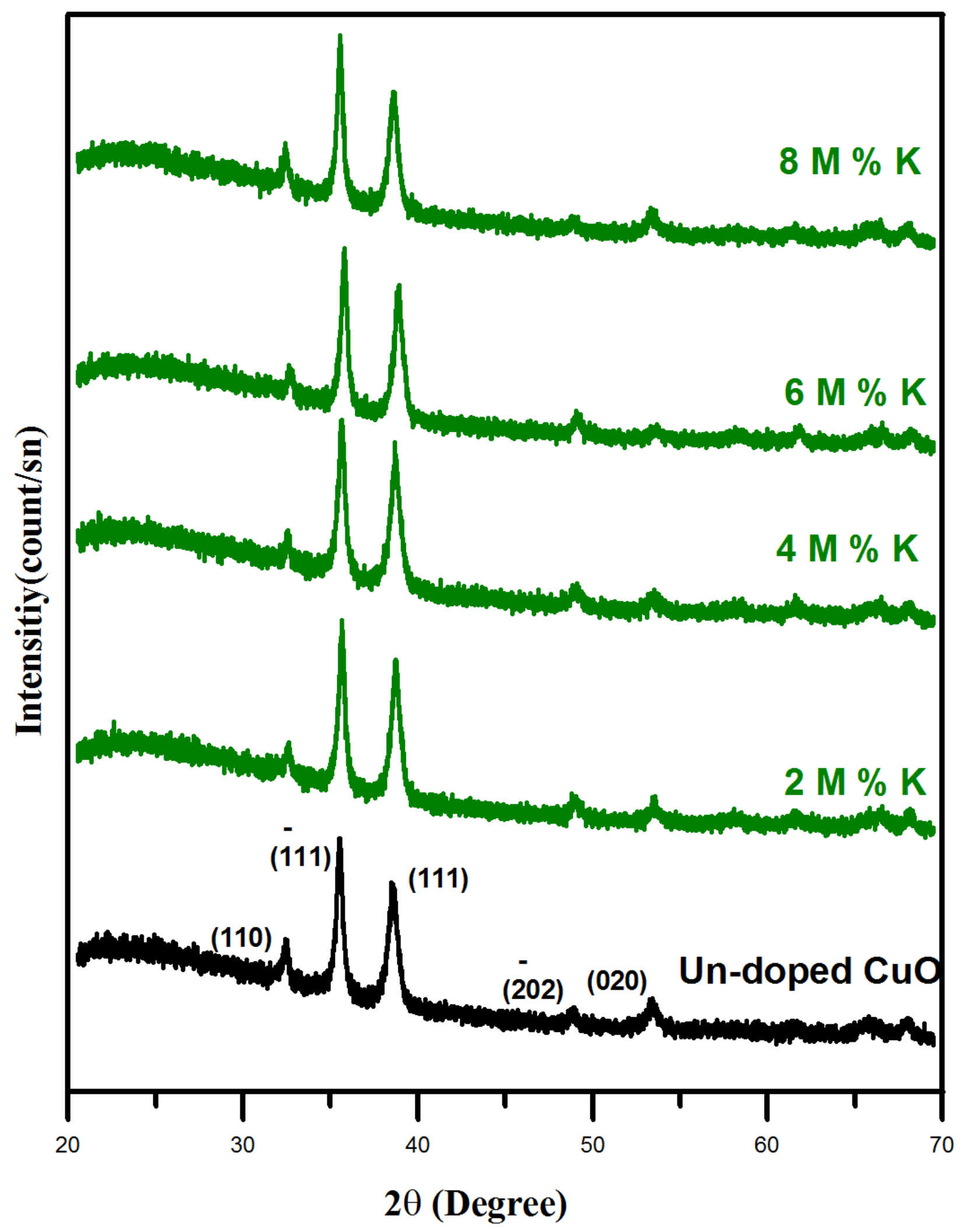

Figure 4: XRD patterns for un-doped and $\mathrm{K}$-doped $\mathrm{CuO}$ films. The peak intensity slightly increases with doping suggesting better crystallinity. 


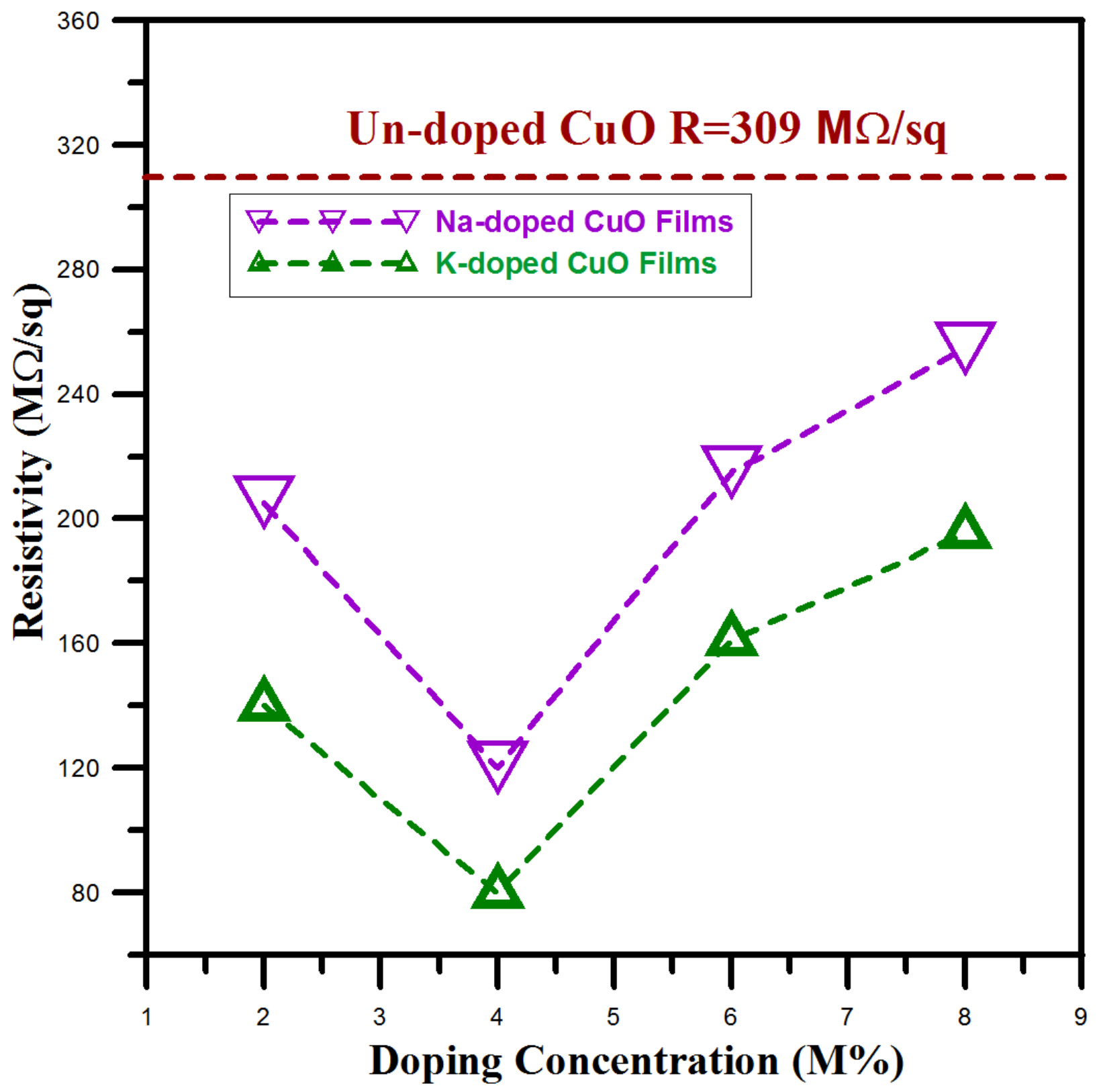

Figure 5: Resistivity values of $\mathrm{CuO}$ films for un-doped and $\mathrm{Na}-$ and $\mathrm{K}$ doping. The decrease in resistivity from $2 \mathrm{M} \%$ to $4 \mathrm{M} \%$ is due to the additional dopants in the films. The increase after $4 \mathrm{M} \%$ for resistivity is potentially due to the carrier traps that are introduced due to high level of doping. 


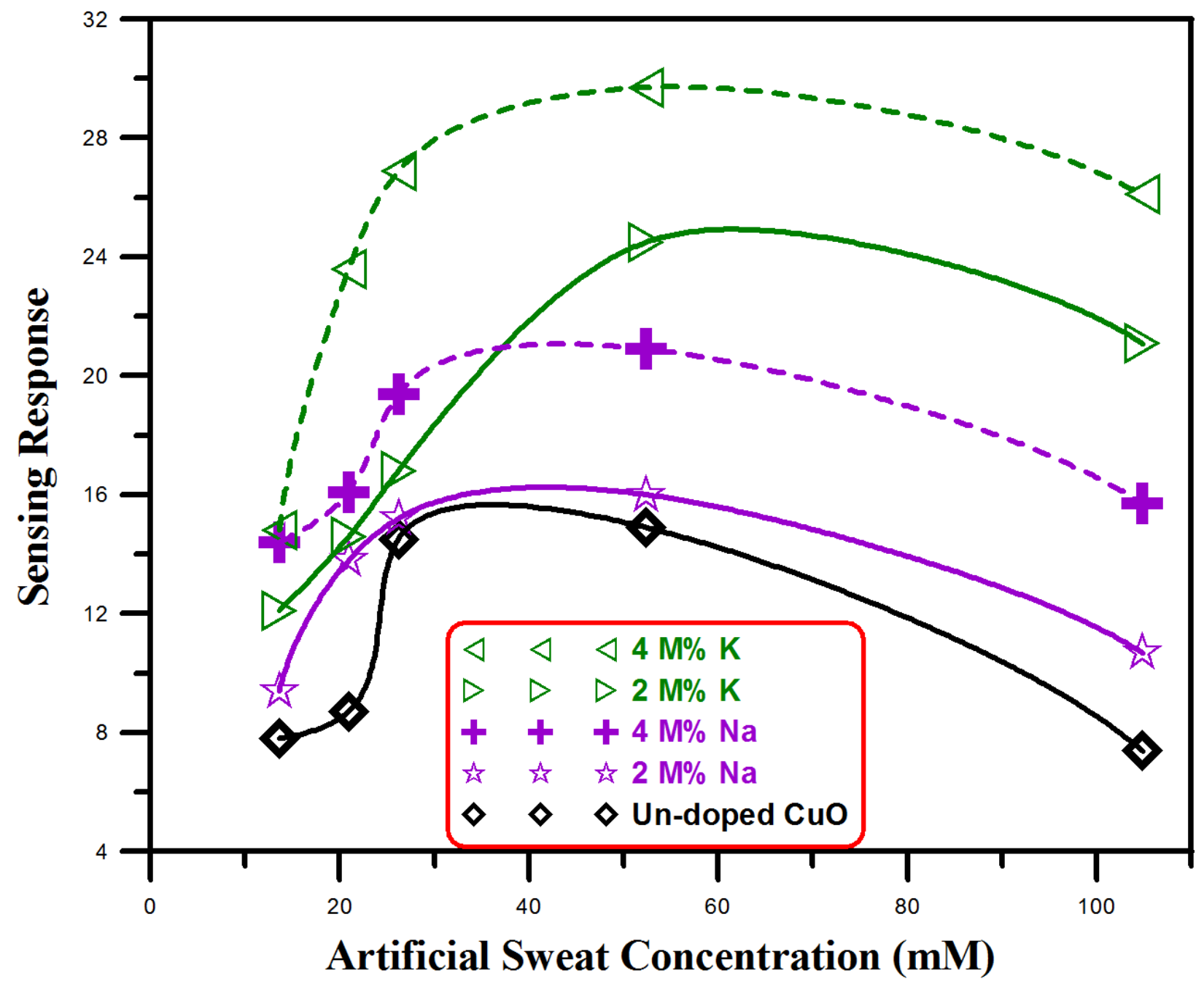

Figure 6: The sensing response of undoped and Na- and $\mathrm{K}$-doped $\mathrm{CuO}$ films were investigated for various artificial sweat concentrations. The sensing response significantly improves with $4 \mathrm{M} \%$ $\mathrm{Na}$ or $\mathrm{K}$ doping. There is a consistent improvement with all doped $\mathrm{CuO}$ films with respect to the un-doped $\mathrm{CuO}$ film. 